\title{
Laparoscopic surgery in the management of choriocarcinoma. A case report
}

\author{
Ana Moreno-Collado • Juan Gilabert-Estellés • \\ Silvana Aniorte-Martinez • Noemí Galindo-Mateu • \\ Marta Molina-Planta • Gema Higueras • \\ Fernando Ruiz-Ripoll
}

Received: 6 April 2010 /Accepted: 19 July 2010 /Published online: 14 September 2010

(C) Springer-Verlag 2010

Keywords Choriocarcinoma - Trophoblastic diseases . Management of choriocarcinoma - Laparoscopic .

Hysterectomy

\section{Background}

Choriocarcinoma is an infrequent, highly malignant neoplasm with an estimated incidence of 2.5 cases each 100,000 pregnancies. Treatment is mainly based on chemotherapy regimens [1]. Hysterectomy, as first-line therapy, could be an option for low-risk patients before or at the time of chemotherapy, decreasing requirements of this last one to the remission of the disease [2, 3]. The majority of women undergoing hysterectomy for malignant gestational trophoblastic desease (GTD) are treated with abdominal hysterectomy [2]. Ovarian removal is not required, since GTD rarely metastasizes to the ovaries and these tumours are not hormonally influenced [2, 4]. Laparoscopic-assisted vaginal hysterectomy has been used in few patients with GTD [5]. This technique allows surveillance of the upper abdomen combined with a shorter acute convalescence than abdominal hysterectomy. In the following case of choriocarcinoma, we proceeded with a laparoscopic approach with the objective

A. Moreno-Collado $(\bowtie) \cdot J$. Gilabert-Estellés ·

S. Aniorte-Martinez $\cdot$ N. Galindo-Mateu $\cdot$ M. Molina-Planta $\cdot$

G. Higueras $\cdot$ F. Ruiz-Ripoll

Department of Gynaecology, HUM La Fe,

N. 1 Pintor Vilar street, 0-5,

46010 Valencia, Spain

e-mail: anitiui9905@hotmail.com of a fast recovery that allowed the initiation of the chemotherapy soon in the postoperative period.

\section{Method}

We report a case of a 41-year-old Caucasian woman, gravida 4 , para 1 , miscarriage 2 , consulting for severe metrorrhagia 6 months after the last miscarriage that required emergency curettage and blood transfusion due to anaemia. The ultrasound showed a heterogeneous endometrium, and BHCG level was $23.592 \mathrm{mIU} / \mathrm{ml}$ at her admission.

\section{Finding(s)}

Pathological findings reported choriocarcinoma so a complete study was performed: $3 \mathrm{HCG}$ level was $72.710 \mathrm{mIU} /$ $\mathrm{ml}$, cranial tomography was normal but chest radiography detected pulmonary metastasis. The patient suffered from new episodes of vaginal haemorrhage requiring more blood transfusions. According to the FIGO 2000 score [6], which was under 6 (low-risk disease), and the presence of active bleeding, and after discussing the options and risks with the patient, a laparoscopic hysterectomy was indicated as primary management of this disease, before starting the chemotherapy treatment. To avoid the dissemination of malignant cells, this surgery was performed without uterine manipulation and the fallopian tubes were coagulated and uterine arteries were ligated at their origin previous to hysterectomy. 
Fig. 1 Evolution of $\beta \mathrm{HCG}$ from time of diagnosis to time when BHCG was negative



Forty-eight hours after surgery, the patient suffered a strong headache and a new cranial CT was performed then, showing a right intraparenchymal parietotemporooccipital haemorrhage that required an urgent craniotomy to evacuate the hematoma. Final pathological anatomy of anomalous cerebral tissue removed during the prior surgery, reported groups of vessels compatible with an arteriovenous malformation, without noticing tumoural fragments neither in the cerebral tissue nor in the hematoma. Brain CT and angio-CT performed 12 days later reported a vasogenic oedema with no evidence of arteriovenous malformations.

Methotrexate was initiated at the Intensive Care Unit under mechanical ventilation. Seventeen days later, the patient recovered consciousness with spontaneous breathing and with a left hemiplegia. High-risk chemotherapy (EMA-CO) was initiated later to prevent the disease progression, with favourable outcomes and disappearance of the disease (Fig. 1).

\section{Conclusion(s)}

Laparoscopic approach to hysterectomy in selected cases of women affected of GTD is a valuable tool in emergency situations in combination with chemotherapy. Metastatic profile of the disease and risk factors must be taken into consideration before any manipulation of the tumour.

\section{Declaration of interest}

The authors report no conflicts of interest. The authors alone are responsible for the content and writing of the paper.

\section{References}

1. Escudero Turpin MA, Blazquez AR, Velasco M, González-Gómez F (2007) Enfermedad trofoblastica gestacional. In: Bajo Arenas JM, Melchor Marcos JC, Mercé LT (eds) Fundamentos de Obstetricia (SEGO). Madrid, Spain, pp 473-487

2. Hammond CB, Weed JC Jr, Currie JL (1980) The role of operation in the current therapy of gestational trophoblastic disease. Am J Obstet Gynecol 136:844-858

3. Suzuka K, Matsui H, litsuka Y et al (2001) Adjuvant hysterectomy in low-risk gestational trophoblastic disease. Obstet Gynecol 97:431-434

4. Berkowitz BJ, Jones JG, Merkatz IR, Runowicz CD (1990) Ovarian conservation in placental site trophoblastic tumour. Gynecol Oncol 37:239-243

5. Lang JF, Children JN, Surwit EA (1995) Laparoscopic hysterectomy for persistent gestational trophoblastic neoplasia. J Am Assoc Gynecol Laparosc 2:475-477

6. FIGO staging for gestational trophoblastic neoplasia 2000 (2002) FIGO Oncology Committee. Int J Gynaecol Obstet 77:285 